\title{
Underwater endoscopic mucosal resection for en bloc resection of a neuroendocrine tumor in the duodenal bulb
}

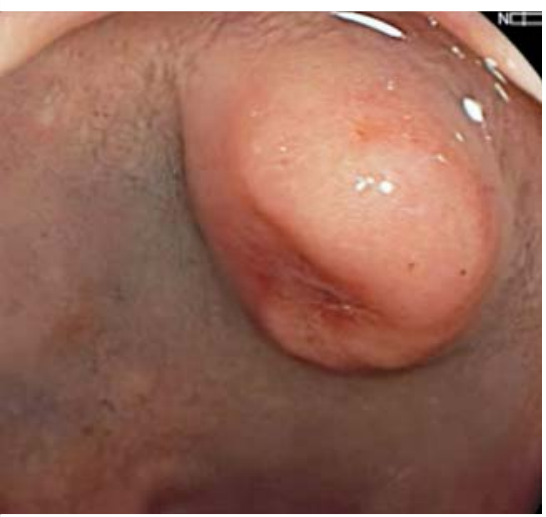

> Fig. 1 A 13-mm ulcerated subepithelial lesion on the superior part of the duodenal bulb. Endoscopic ultrasound-guided fine-needle aspiration showed a neuroendocrine tumor confined to the submucosal layer.

Duodenal neuroendocrine neoplasms (d-NENs) may be sporadic or associated with multiple endocrine neoplasia type 1 $[1,2]$. Classification, based on morphology and proliferation rate, includes welldifferentiated neuroendocrine tumors (NETs; G1-G3) and poorly differentiated neuroendocrine carcinomas (G3).

Endoscopic resection is indicated in nonampullary $\mathrm{d}$-NENs $\leq 10 \mathrm{~mm}$ that are confined to the submucosa and without lymph node or distant metastasis, and could be considered in selected cases for lesions 10-19 mm [2,3].

Underwater endoscopic mucosal resection (UEMR) without submucosal injection was described by Binmoeller for colorectal polyps and duodenal adenomas [4, 5]. We present the case of a 64-year-old man with a 13-mm NET ( $>$ Fig. 1), confined to the submucosal layer in the duodenal bulb, after endoscopic ultrasoundguided fine-needle aspiration. The lesion was tattooed and referred for surgical and oncological evaluation. There were no signs of lymph node metastasis on computed tomography. After multidisciplinary team discussion, endoscopic resection was planned.

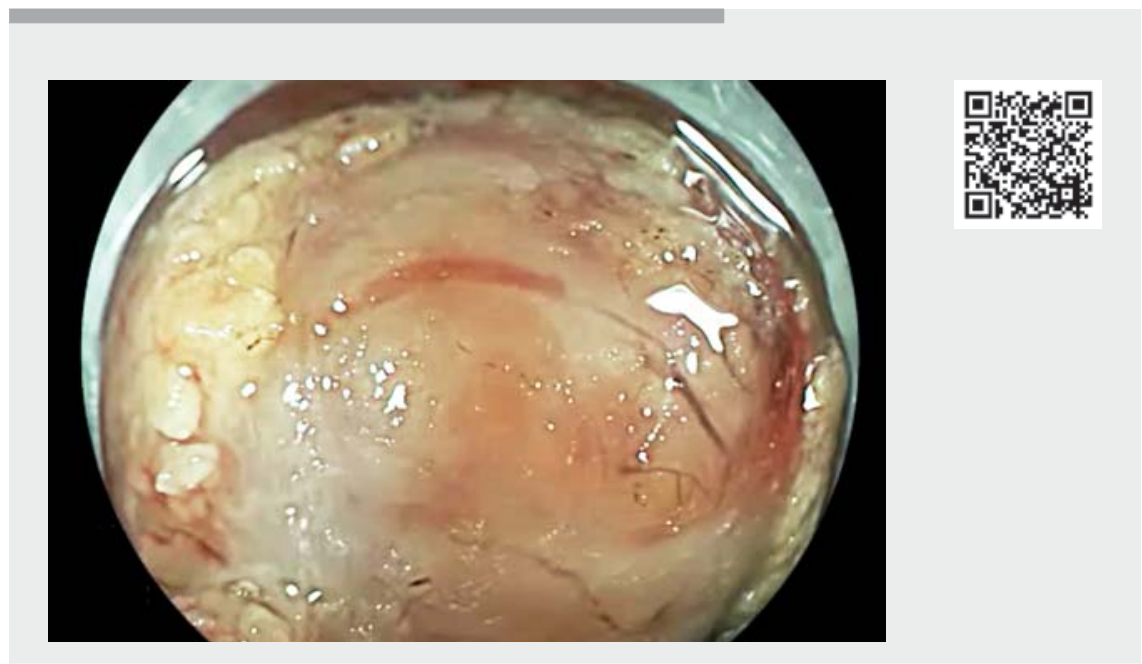

Video 1 En bloc underwater endoscopic mucosal resection of a neuroendocrine tumor in the duodenal bulb.

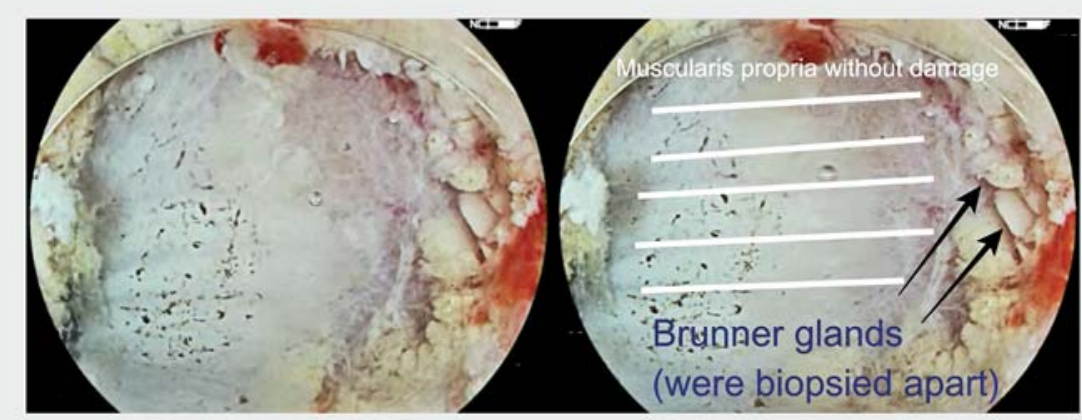

- Fig. 2 The mucosal defect after underwater endoscopic mucosal resection. Intact muscularis propria can be seen, as well as some hypertrophic Brunner glands on the margin.

Upper endoscopy was performed under propofol sedation using a gastroscope (EG-760Z; Fujifilm, Tokyo, Japan). An aspiration test was performed with a band ligator cap (Captivator EMR; Boston Scientific, Marlborough, Massachusetts, USA) but the lesion did not enter the cap.UEMR was then attempted using a short straight cap ( $\triangleright$ Video 1 ). Gas was aspirated and the duodenal bulb was filled with sterile water. The lesion was easily snared underwater using a rounded 15-mm snare (Captivator II; Boston Scientific) and resected using Endocut Q effect 2 (VIO 300, ERBE Elektromedizin, Tübingen, Germany). The specimen $(13 \times 10 \times$ $9 \mathrm{~mm}$ ) was retrieved using the same snare, and the mucosal defect was clipped ( $>$ Fig. 2, \Video 1). There were no complications, and the asymptomatic patient was discharged after 24 hours. Final histology showed a 10-mm well-differentiated G1 NET with free margins. 
UEMR might be an adequate technique for en bloc resection of 10-mm d-NENs and an alternative to ligation-assisted EMR or endoscopic submucosal dissection.

Endoscopy_UCTN_Code_TTT_1AO_2AG

\section{Competing interests}

The authors declare that they have no conflict of interest.

The authors

Hugo Uchima ${ }^{1,2}$, Alberto Diez-Caballero ${ }^{3}$, Jaume Capdevila ${ }^{4}$, Mercé Rosinach ${ }^{1}$, Alfredo Mata', Román Turró1 ${ }^{1}$, Jorge Espinós ${ }^{1}$

1 Endoscopy Unit, Teknon Medical Center, Barcelona, Spain

2 Hospital Universitario Germans Trias i Pujol, Badalona, Spain

3 Gastrointestinal Surgery Unit, Teknon Medical Center, Barcelona, Spain

4 Teknon Oncology Institute, Teknon Medical Center, Barcelona, Spain
Corresponding author

\section{Hugo Uchima, MD}

Endoscopy Unit, Teknon Medical Center, Vilana 12 Planta 1, Barcelona 08017, Spain huchima.germanstrias@gencat.cat

\section{References}

[1] Pavel M, Öberg K, Falconi M et al. Gastroenteropancreatic neuroendocrine neoplasms: ESMO Clinical Practice Guidelines for diagnosis, treatment and follow-up. Ann Oncol 2020; 31: 844-860

[2] Delle Fave G, O'Toole D, Sundin A et al. ENETS consensus guidelines update for gastroduodenal neuroendocrine neoplasms. Neuroendocrinology 2016; 103: 119-124

[3] Wang R, Mohapatra S, Jovani M et al. Risk factors for lymph node metastasis and survival of patients with nonampullary duodenal carcinoid tumors treated with endoscopic therapy versus surgical resection: analysis of the Surveillance, Epidemiology, and End Results program. Gastrointest Endosc 2021. doi:10.1016/j.gie.2020.12.012

[4] Binmoeller KF, Weilert F, Shah J et al. "Underwater" EMR without submucosal injection for large sessile colorectal polyps (with video). Gastrointest Endosc 2012; 75: 10861091

[5] Binmoeller KF, Shah JN, Bhat YM et al. "Underwater" EMR of sporadic laterally spreading nonampullary duodenal adenomas (with video). Gastrointest Endosc 2013; 78: 496502
Bibliography

Endoscopy 2022; 54: E264-E265

DOI 10.1055/a-1512-8954

ISSN 0013-726X

published online 18.6.2021

(C) 2021. Thieme. All rights reserved.

Georg Thieme Verlag KG, Rüdigerstraße 14, 70469 Stuttgart, Germany

\section{ENDOSCOPY E-VIDEOS}

https://eref.thieme.de/e-videos

口厚回 Endoscopy E-Videos is an open access online section, 靣触: reporting on interesting cases and new techniques in gastroenterological endoscopy. All papers include a high quality video and all contributions are freely accessible online. Processing charges apply (currently EUR 375), discounts and wavers acc. to HINARI are available.

This section has its own submission website at https://mc.manuscriptcentral.com/e-videos 